\title{
Anti-trafficking Efforts and Colonial Violence in Canada
}

\author{
Katrin Roots
}

Review of: Responding to Human Trafficking: Dispossession, Colonial Violence, and Resistance among Indigenous and Racialized Women, Julie Kaye, 2017, University of Toronto Press, 978-1487521615.

Suggested citation: K Roots, 'Anti-trafficking Efforts and Colonial Violence in Canada', Anti-Trafficking Review, issue 12, 2019, pp. 201-204, www.antitraffickingreview.org

In Responding to Human Trafficking: Dispossession, Colonial Violence, and Resistance among Indigenous and Racialized Women, Julie Kaye offers a critical examination of how Canadian state and non-state actors understand human trafficking and implement anti-trafficking measures. Kaye examines Canada's antitrafficking policies and the efforts of non-government organisations (NGOs) through one-on-one interviews and focus group discussions. She demonstrates the way in which this politically charged issue has worked to conceal Canada's violent colonial history and naturalise the inequalities and structural and material conditions in which trafficking and various forms of violence occur. Kaye argues that trafficking discourses position the colonial state as the saviour and therefore work to reinforce its power.

The book begins with a powerful foreword by Sarah Hunt ${ }^{1}$ who reminds us that the strength and resilience of Indigenous peoples are being undermined by anti-trafficking responses. Such responses construct Indigenous women, youth, and Two-Spirit ${ }^{2}$ people as always and already 'at risk' of experiencing

1 Sarah Hunt is an assistant professor in First Nations and Indigenous Studies and the Department of Geography at the University of British Columbia. Her work, which focuses on Indigenous and legal geographies, critically takes up questions of justice, gender, self-determination, and the spatiality of Indigenous law. She has written several articles on the role of the anti-trafficking framework on Indigenous communities.

2 'Two-Spirit' person is a term used by some Indigenous people to identify themselves as having both masculine and feminine spirits. 
violence through their 'own choices' to engage in risky behaviours such as drug and alcohol use and sex work. When responses to trafficking are presented as yet another form of state-led rescue, Hunt argues, they do more to harm Indigenous women, youth, and Two-Spirit people by contributing to the naturalisation of Indigenous communities as sites of violence, criminalising them, forcing them into state protection, and casting them as in need of rescue by the colonial state. As Hunt points out, the way forward for Indigenous peoples is not through attempts to save or rescue them but by dismantling 'the oppressive system that created conditions from which we need to heal' (p. xiv).

In Responding to Human Trafficking, Kaye contributes to trafficking scholarship in several important ways. Most notably, this book offers a unique perspective on trafficking by focusing on how anti-trafficking frameworks reproduce structures of domination that naturalise settler colonialism in Canada. Kaye points out the contradiction between the frequently made argument that antitrafficking policies are working to address colonial legacies and the reality that they work to maintain colonial relations, and, in effect, undermine and impede the ongoing resistance of marginalised communities.

Second, Kaye notes an important shift in the Canadian context, from a focus on international trafficking to an increasingly prevalent emphasis on domestic trafficking. By providing specific examples of this shift through concerns over child sexual exploitation, sex work, and violence against women, especially Indigenous women, Kaye asks, 'in the context of settler colonialism, what are the implications of representing specific subjects as internal or domestic as opposed to international or global?' (p. 5). She argues that the over-arching focus on violence against women within the anti-trafficking framework enables the erasure of systemic forms of discrimination and indeed 'naturalizes the national, racial and sexual priorities of a settler colonial state' (p. 17). This is accomplished by emphasising the efforts aimed at the 'at risk' subject-a gendered, raced, and classed subject constructed overwhelmingly as an Indigenous woman or girl. While this approach appears to highlight the overwhelming violence inflicted on Indigenous women and girls, the focus of anti-trafficking responses on individual traffickers as offenders conceals the state's role in establishing and maintaining the structures of domination that enable this violence.

Third, Kaye rightly argues for the need to understand international and domestic trafficking discourses not as two separately operating discourses but, rather, as intersecting and mutually constitutive. As she argues in Chapter Three, these discourses operate simultaneously to criminalise non-citizens and other marginalised individuals. For instance, discourses around international trafficking justify the implementation of stricter immigration policies in the name of national security and public safety while simultaneously 
building up the image of Canada as a good, kind, and helpful nation, thus concealing the violence of its colonial history. In contrast, discourses around domestic trafficking enable the targeting of the sex trade through anti-trafficking interventions. Yet, this separation between the international and domestic trafficking discourses serves to conceal the reproduction of the settler colonial state through modes of inclusion and exclusion. Kaye demonstrates that local understandings and responses to trafficking challenge our ability to use binaries such as international/domestic, victim/agent, or consent/coercion, since they involve far more nuances, complexities, and site-specific variations.

Finally, Kaye's research is an important empirical contribution to the antitrafficking literature, particularly in the Canadian context. While scholarship on trafficking has seen significant growth in recent years, there is a notable lack of substantive empirical work on the topic in Canada. ${ }^{3}$ Therefore, Kaye's book, based on 56 interviews and two focus groups with front-line antitrafficking service providers, government agencies, and law enforcement in three Canadian provinces, Manitoba, British Columbia and Alberta, provides much needed insight into the ways in which trafficking is being addressed in a localised context.

My one critique of the book relates to Kaye's conceptualisation of the Canadian state. While she notes that different state actors held varied understandings of trafficking, her analysis tends to reproduce a reified understanding of the Canadian state grounded in the assumption that it is unified when initiating and negotiating anti-trafficking responses. On balance, however, the book makes an important contribution to anti-trafficking scholarship in Canada. Given its reliance on empirical research at the localised level, it enables us to gain a better understanding of on-the-ground impact of anti-trafficking laws and policies. Kaye's examination of anti-trafficking responses in the context of Canada's settler-colonial history and the role of anti-trafficking initiatives in the continued reproduction of colonial relations offers new and insightful perspectives on the particular ways in which Canadian anti-trafficking measures operate to ensure the ongoing inequality of and violence against Indigenous peoples. The book will be useful to students, teachers, researchers, and, hopefully, policy makers alike.

3 See, for example, H Millar, T O'Doherty and K Roots, 'A Formidable Task: Reflections on obtaining legal empirical evidence on human trafficking in Canada', Anti-Trafficking Review, issue 8, 2017, pp. 34-49, https://doi.org/ 10.14197/atr.20121783; K Roots, The Human Trafficking Matrix: Law, policy and anti-trafficking practices in the Canadian criminal justice system, Doctoral Dissertation, York University, Toronto, ON, 2018. 
Katrin Roots is a Social Science and Humanities Research Council of Canada Post-Doctoral Research Fellow at Carleton University, Ottawa. Her postdoctoral project examines the criminal justice and immigration consequences of human trafficking charges and convictions in Canada. Katrin recently received her PhD in Socio-Legal Studies from York University, Toronto, defending her doctoral dissertation entitled The Human Trafficking Matrix: Law, Policy and Anti-Trafficking Practices in the Canadian Criminal Justice System. Her work on human trafficking has been published in the Canadian Journal of Law and Society, Atlantis: Critical Studies in Gender, Culture and Social Justice, and Anti-Trafficking Review.Email: kroots@yorku.ca. 